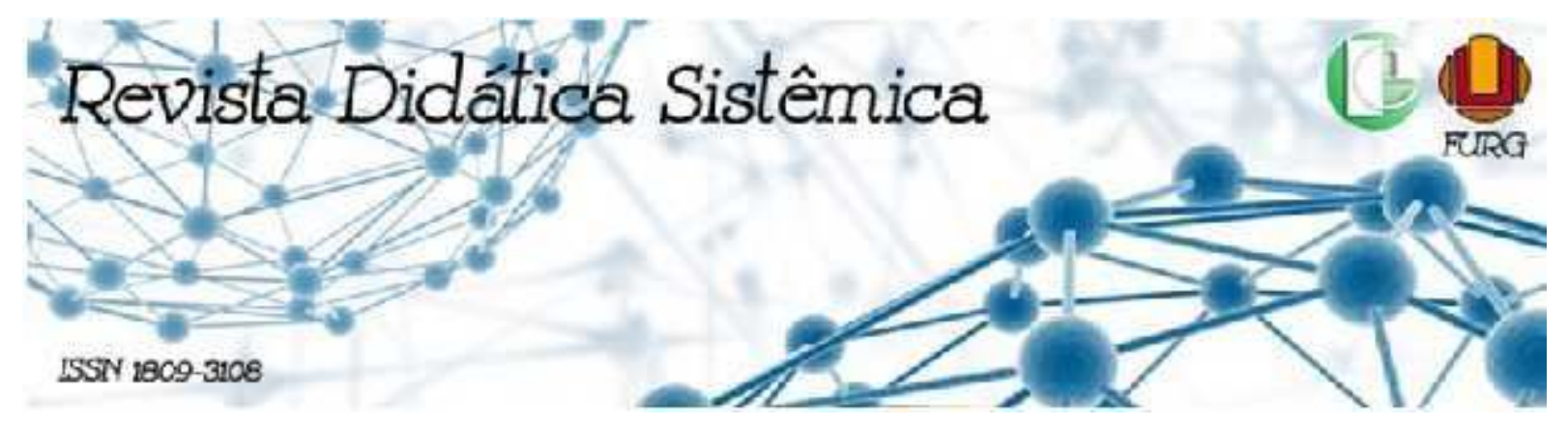

\title{
EDUCAÇÃO FÍSICA NA EDUCAÇÃO INFANTIL: SOBRE MOVIMENTO, AMPLIAÇÃO DE REPERTÓRIOS E DESAFIOS DO COTIDIANO PEDAGÓGICO
}

Juliano Silveira ${ }^{1}$

\section{RESUMO}

O presente ensaio objetiva refletir sobre a importância das práticas pedagógicas desenvolvidas por professores de Educação Física no âmbito da educação infantil. Nessa perspectiva, consideram-se os sentidos e os significados atribuídos ao movimento humano, o direito ao acesso à cultura corporal de movimento e os desafios do cotidiano pedagógico dessa etapa da educação básica. As discussões indicam a necessidade de diálogos em torno da construção de uma Educação Física da educação infantil, superando representações equivocadas sobre o seu papel e possibilitando uma docência compartilhada.

Palavras-chave: Cultura corporal de movimento; Infância; Docência compartilhada.

\section{PHYSICAL EDUCATION IN CHILDHOOD EDUCATION: ABOUT MOVEMENT, EXPANDING REPERTORIES AND CHALLENGES OF PEDAGOGICAL DAILY}

\begin{abstract}
This essay aims to reflect on the importance of pedagogical practices developed by Physical Education teachers in the context of early childhood education. From this perspective consider the senses and meanings attributed to the human movement, the right to access body culture of movement and the challenges of the pedagogical daily life of this stage basic education. The discussions indicate the need for dialogues around the construction of Physical Education in early childhood education, overcoming misunderstandings about their role and enabling shared teaching.
\end{abstract}

Keywords: Movement body culture; Childhood; Shared teaching.

\section{LA EDUCACIÓN FÍSICA EN LA EDUCACIÓN INFANTIL: SOBRE EL MOVIMIENTO, LA EXPANSIÓN DE REPERTORIOS Y LOS DESAFÍOS DE LA PEDAGÓGICA COTIDIANA}

\section{RESUMEN}

Este ensayo tiene como objetivo reflexionar sobre la importancia de las prácticas pedagógicas desarrolladas por los docentes de Educación Física en el contexto de la educación infantil. Desde esta perspectiva, se considera los sentidos y significados atribuidos al movimiento humano, el derecho al acceso a la cultura corporal del movimiento y los desafíos de la cotidianidad pedagógica. vida de esta etapa de la educación básica. Las discusiones señalan la necesidad de dialogar en torno a la construcción de la Educación Física en la educación infantil, superando las tergiversaciones sobre su rol y posibilitando la enseñanza compartida.

Palabras clave: Movimiento cuerpo cultura; Infancia; Enseñanza compartida.

\footnotetext{
${ }^{1}$ Doutor em Educação Física pela Universidade Federal de Santa Catarina. Professor da Rede Municipal de Ensino de Florianópolis.
} 


\section{INTRODUÇÃO}

A presença da Educação Física, no âmbito da educação infantil, tem sido tema de debates nas diferentes redes de ensino, assim como entre os pesquisadores da área que têm se dedicado a refletir sobre essa etapa específica da educação básica. Tais debates contemplam a sua legitimidade, uma vez que tratamos de um componente curricular específico numa etapa da educação básica que não se estrutura através de disciplinas; e também, a sua organização, pensando nos tempos e espaços, metodologias, as relações com as equipes docentes e pedagógicas/gestoras. Da mesma forma, fazem-se presentes, nessas discussões, questões curriculares, contemplando as expectativas pedagógicas em relação à Educação Física, suas especificidades curriculares, e possíveis diálogos e coerência com a $\mathrm{BNCC}^{2}$ e/ou outras orientações de cunho curricular.

O aumento significativo no número de incursões investigativas ${ }^{3}$ e publicações, ao longo das duas últimas décadas, ${ }^{4}$ que têm tematizado as relações entre Educação Física e educação infantil, parecem ser um indicativo das muitas problematizações sobre as quais nosso campo ainda precisa se debruçar no que tange à produção do conhecimento. Consequentemente, indica, também, uma série de questões que precisam ser enfrentadas cotidianamente pelos professores e professoras de Educação Física que desenvolvem suas práticas pedagógicas na primeira etapa da educação básica.

Ao considerarmos a centralidade do corpo em movimento ${ }^{5}$, assim como as brincadeiras e interações, nas ações pedagógicas desenvolvidas na esfera da educação de zero a cinco anos, defendemos que as práticas pedagógicas tendem a ser qualificadas consideravelmente com a integração de professores e professoras de Educação Física nas Unidades Educativas. Isso porque, dos diálogos a partir das especificidades de sua área de formação com as expectativas curriculares da educação infantil, podem surgir bons frutos em termos de vivências a serem acumuladas pelas crianças, na perspectiva da ampliação do seu repertório cultural.

Assim sendo, o objetivo do presente ensaio é refletir sobre a importância das práticas

\footnotetext{
${ }^{2}$ Base Nacional Comum Curricular.

${ }^{3}$ Em estudo realizado por Farias et al (2019), constatou-se que as produções acadêmicas, no âmbito da Pósgraduação, acerca das relações entre Educação Física e educação infantil, aumentaram, consideravelmente, entre os anos de 2006 e 2018.

${ }^{4}$ Ver, por exemplo: Silveira (2015), Mello et al (2012; 2016; 2018), Macedo e Neira (2017), Perini e Bracht (2016), Oliveira e Prodócimo (2016), Souza (2019) e Ota (2020).

5 A adoção do termo "corpo em movimento" tem como intuito demarcar as expressões corporais das crianças em suas ações comunicativas (especialmente, entre os bebês), assim como as suas intencionalidades ao se movimentarem em vivências diretamente relacionadas com as práticas corporais.
} 
pedagógicas desenvolvidas por professores (as) de Educação Física no âmbito da educação infantil, na perspectiva de uma ampliação do repertório de vivências com o corpo em movimento. Para tal, as discussões contemplam os sentidos e significados que a Educação Física atribui ao movimento humano e a sua importância para o desenvolvimento das crianças; o direito ao acesso à cultura corporal de movimento no âmbito da educação institucionalizada; e os contornos assumidos por uma Educação Física da educação infantil, considerando os desafios enfrentados, cotidianamente, nas Unidades Educativas.

\section{OS SENTIDOS E SIGNIFICADOS QUE A EDUCAÇÃO FÍSICA ATRIBUI AO MOVIMENTO HUMANO E SUA IMPORTÂNCIA PARA O DESENVOLVIMENTO DE CRIANÇAS DE ZERO A CINCO ANOS}

Primeiramente, é preciso considerar a importância da presença dos professores de Educação Física na educação infantil, ligada aos sentidos e significados que são atribuídos ao movimento humano a partir do olhar dessa área específica de formação. Nesse sentido, podese refletir sobre as contribuições para as aprendizagens e desenvolvimento das crianças, tendo como base a compreensão do movimento humano como linguagem. As suas diferentes formas de expressão podem ser potencializadas, assumindo como referência as contribuições dessa área de formação específica.

De fato, ao refletirmos sobre a legitimidade desses profissionais no cotidiano pedagógico da educação de zero a cinco anos, é preciso atentar para as contribuições de sua área específica para o trato pedagógico com as crianças nessa etapa da educação básica. De acordo com Silveira (2015),

[...] a legitimidade da presença do professor de Educação Física na educação infantil aponta justamente para aquilo que qualifica suas intervenções em detrimento de qualquer semelhança com a ação pedagógica de outros profissionais, isto é, as bases conceituais didático-pedagógicas específicas da Educação Física acerca do trato com o corpo e o movimento humano (SILVEIRA, 2015, p.18).

Nessa perspectiva, a Educação Física compreende o corpo em movimento, cuja expressão máxima são as práticas corporais como manifestações das possibilidades expressivas dos sujeitos, produzidas por diversos grupos sociais no decorrer da história. Assim, o movimento humano está sempre inserido no âmbito da cultura e a vivência das práticas corporais oferece aos sujeitos o acesso a uma dimensão de conhecimentos e de experiências que não teria de outro modo (BRASIL, 2018). 
Compreender o movimento humano, com base nesse viés, tende a valorizar as atividades lúdicas e o protagonismo das crianças, sua participação, expressão, criação e manifestação de interesses, como sujeitos ativos em seus processos de aprendizagem e desenvolvimento. Isso porque nossas intencionalidades pedagógicas assumem como centralidade os seres humanos de pouca idade que se movimentam.

Soma-se a isso o fato de que o movimento é a principal linguagem de que as crianças pequenas dispõem em seus primeiros anos de vida (MELLO et al, 2012), o que parece justificar assim, ainda mais, as contribuições da Educação Física, a partir desse viés, para o desenvolvimento integral dos pequenos cidadãos. Nessa perspectiva, é possível afirmar que as vivências com o movimento acabam configurando uma parte privilegiada da experiência infantil (MELLO et al, 2018), uma vez que, através de seus corpos em movimento, interagem, constroem conhecimentos, afirmam suas identidades, internalizam e produzem cultura.

Esses sentidos e significados atribuídos ao movimento humano também corroboram com uma perspectiva de ampliação do repertório cultural das crianças, tendo em vista que os momentos de Educação Física tendem a representar "o lócus de apropriação da variedade de formas pelas quais a cultura lúdica se expressa” (MACEDO; NEIRA, 2017, p.99).

Outro ponto a ser destacado quanto à presença da Educação Física, no âmbito da educação infantil, diz respeito ao fato do movimento poder constituir-se em eixo articulador dos diferentes campos de experiência (BRASIL, 2018) a serem contemplados nas práticas pedagógicas voltadas aos pequenos. Nessa perspectiva, as próprias abordagens didáticopedagógicas da Educação Física, nessa etapa da educação básica, podem articular, metodologicamente, os diferentes campos de experiência preconizados como expectativas curriculares, assumindo como referência o movimento humano. Ou seja, as práticas corporais, especificidade da Educação Física (NOGUEIRA, 2005), podem assumir centralidade da articulação desses diferentes saberes, envolvendo as relações sociais, culturais e identidades (o eu, o outro e o nós); as linguagens visuais, sonoras (traços, sons, cores e formas), orais e escritas (escuta, fala, pensamento e imaginação), além das relações com natureza (espaço, tempo, quantidade, relações e transformações) (BRASIL, 2018).

Um exemplo apropriado, na presente perspectiva, é o estudo recente de Ota (2020), que problematizou como a Educação Física, por meio da abordagem de "histórias vivenciadas" na educação infantil, pode englobar elementos inerentes aos diferentes campos de experiências da BNCC em uma proposta pedagógica que assume o movimento como centralidade.

Por fim, é importante salientar que, ao defendermos o "diferencial pedagógico" da 
presença dos professores de Educação Física na educação infantil, é preciso considerar que tratamos de uma construção epistemológica ligada a uma área de formação e dos possíveis reflexos da apreensão de suas bases teóricas e metodológicas pelos professores para a efetivação do seu fazer pedagógico no cotidiano da educação infantil.

Se as licenciaturas em Educação Física não abordam esse componente curricular a partir da perspectiva aqui defendida, uma vez que os currículos de graduação se constituem em um espaço permanente de disputas entre concepções teóricas, isso acaba dificultando a sua apreensão entre os professores em formação. E isso costuma refletir, diretamente, nos cotidianos pedagógicos da educação infantil, uma vez que os saberes dos professores de Educação Física, atuantes nessa etapa da educação básica, se referenciam no que foi abordado durante a formação inicial, assim como em experiências de vida anteriores ao ingresso na graduação (OLIVEIRA; PRODÓCIMO, 2016).

Todavia, consideramos que o processo de formação docente possui um caráter permanente que vai muito além dos cursos de licenciatura e que tende a se beneficiar dos processos formativos ligados à própria prática pedagógica. E, assim sendo, reiteramos a defesa da tese de que a inserção e atuação profissional, no âmbito da educação infantil, se constitui em uma via de mão dupla, na qual as possibilidades pedagógicas da educação de zero a cinco anos se enriquecem com a presença da Educação Física, e em que a própria Educação Física se transforma pedagogicamente e qualifica as suas ações ao dialogar com as especificidades da educação infantil.

\section{SOBRE O DIREITO DE ACESSO ÀS PRÁTICAS CORPORAIS NA EDUCAÇÃO INSTITUCIONALIZADA: A CULTURA CORPORAL DE MOVIMENTOS}

Outro argumento favorável à presença dos professores de Educação Física, nessa etapa da educação básica, está relacionado com a compreensão de que as crianças que frequentam as unidades de educação infantil se constituem em sujeitos que têm direito de acessar aos conhecimentos historicamente produzidos no âmbito da cultura corporal de movimento. De fato, "a oferta de tais conhecimentos sistematizados historicamente se constitui em dever da educação institucionalizada e por sua vez, em direito daqueles que frequentam as instituições educativas" (SILVEIRA, 2015, p.19).

Assim, é possível afirmar que, desde a mais tenra idade, a especificidade do trabalho pedagógico da Educação Física, nessa etapa da educação básica, tem como intuito ampliar o 
repertório de vivências das crianças, com enfoque especial nos conhecimentos inerentes às práticas corporais. Segundo Buss-Simão (2005, p.164), "os fenômenos da cultura que se expressam a nível corporal, bem como a ampliação, a vivência e a criação das culturas infantis de movimento, constituem a especificidade da contribuição da Educação Física na Educação Infantil”.

Dessa forma, a citada perspectiva de uma ampliação de repertórios passa pela abordagem das diversas práticas corporais produzidas pela humanidade que podem ser vivenciadas por meio da expressão corporal. E assim sendo, mais uma vez, compreender o movimento humano como linguagem e sua abordagem pedagógica, alocada na esfera de uma perspectiva cultural, parece atender a essa demanda curricular e, por sua vez, parece exigir as contribuições didático-pedagógicas de professores oriundos de uma área específica, ou seja, a Educação Física. De acordo com Souza (2019),

Nesta perspectiva, o professor de Educação Física possui um papel social,
materializado pelo compromisso político e pedagógico de possibilitar às
crianças inseridas nas instituições escolares o acesso aos conhecimentos sobre
os Jogos, Brinquedos e Brincadeiras, a Dança, a Ginástica, as Lutas, o Esporte,
as Práticas Corporais de Aventura, dentre outros elementos. A inserção deste
professor na Educação Infantil não modifica este papel social, cabendo ao
mesmo compreender as especificidades que permeiam estes espaços, bem
como, as características biopsicossociais que marcam a infância, elaborando
um trabalho educativo que se paute pela práxis e pela intencionalidade
pedagógica (SOUZA, 2019, p.04).

Almeja-se, assim, como meta de nossas ações na educação de zero a cinco anos, uma intencionalidade pedagógica, cujo compromisso seja possibilitar que as crianças deixem das unidades educativas com um repertório de vivências culturais pautadas no movimento, quantitativamente e qualitativamente superior do que quando ingressaram, contribuindo para o seu desenvolvimento integral. E, na perspectiva de uma coerência com as especificidades dessa faixa-etária, respeitando os interesses e necessidades das crianças, assumimos as brincadeiras como meio de ampliação do citado repertório cultural. Concordamos, desse modo, com Mello et al (2018) ao defenderem que,

[...] as manifestações da cultura lúdica infantil, expressas por meio dos jogos e das brincadeiras, constituem o eixo pelo qual o trabalho pedagógico na Educação Infantil deva se articular. Assim sendo, devido à natureza epistemológica do seu objeto de estudo, de suas práticas pedagógicas acumuladas e dos conhecimentos produzidos, a Educação Física é um campo imprescindível para a primeira etapa da Educação Básica no Brasil (MELLO et al, 2018, p.25). 
É preciso ressaltar que as expectativas curriculares em torno da educação de zero a cinco anos envolvem a abordagem de uma série de linguagens (visuais, orais, escritas, sonoras e corporais) que precisam ser desenvolvidas pelas equipes docentes responsáveis pelos diferentes grupos de crianças, respeitando suas especificidades etárias. Assim sendo, é de se esperar que, embora o "corpo em movimento" esteja diretamente relacionado com a especificidade pedagógica da Educação Física, as pedagogas também tenham que contemplá-lo em seus planejamentos. Por isso, a importância das ações a serem desenvolvidas na educação infantil se pautarem em uma perspectiva de complementariedade, na qual os esforços de diferentes profissionais se somem para enriquecer as experiências das crianças no cotidiano pedagógico das Unidades Educativas. Conforme Sayão (2002),

[...] só se justifica a necessidade de um/a professor/a dessa área na Educação Infantil se as propostas educativas que dizem respeito ao corpo e ao movimento estiverem plenamente integradas ao projeto da instituição, de forma que o trabalho dos adultos envolvidos se complete e se amplie visando possibilitar cada vez mais experiências inovadoras que desafiem as crianças (SAYÃO, 2002, p.59).

Esses diálogos entre diferentes professores, nas equipes pedagógicas, podem ser importantes no sentido de que as ações com o corpo em movimento, desenvolvidas para além dos momentos de Educação Física, passem a incorporar elementos teórico-metodológicos que qualifiquem as ações das pedagogas, ao se permitirem aprender com colegas professores de outra área. E nesse caso, a recíproca é verdadeira, uma vez que as ações da Educação Física com os pequenos acabam beneficiando-se, também, a partir do olhar e das experiências das pedagogas no trato pedagógico com outras demandas curriculares.

\section{OS CONTORNOS ASSUMIDOS POR UMA EDUCAÇÃO FÍSICA QUE SE PRETENDE "COM A EDUCAÇÃO INFANTIL"': REFLETINDO SOBRE DESAFIOS DO COTIDIANO PEDAGÓGICO}

As discussões, no âmbito da educação infantil, têm contemplado uma preocupação em torno de "assumirmos já, na Educação Infantil, um modelo organizado em disciplinas e afinado com uma abordagem fragmentária de conhecimento que tende a compartimentar a criança"

\footnotetext{
${ }^{6}$ A expressão "com a educação infantil” é adotada visando expressar uma compreensão acerca do papel da Educação Física no âmbito da educação infantil que represente uma perspectiva pautada em diálogos e partilhas, "um fazer com", tanto em termos de expectativas curriculares, propostas desenvolvidas com outros professores e, também, construídas e vivenciadas com as crianças.
} 
(AYOUB, 2005, p.144). Da mesma forma, incluem entendimentos de que uma fragmentação dos objetos de estudo entre profissionais de áreas de atuação que não se ligam, inviabilize os diálogos entre os trabalhos realizados pelos professores em sala (GUIRRA; PRODOCIMO, 2010). E, também, temores quanto a "uma disciplinarização da educação infantil com a presença do professor especialista, a exemplo do que ocorre nos outros níveis de ensino" (OLIVEIRA; PRODÓCIMO, 2016, p.38).

No entanto, segundo Sayão (2002, p.05), “o problema está nas concepções de trabalho pedagógico destes/as profissionais que, geralmente, fragmentam as funções de uns e outros, isolando-se em seus próprios campos". E é preciso salientar que a forma como os diferentes direitos de aprendizagens serão garantidos no trato pedagógico da educação infantil, assim como a proposta de abordagem dos diferentes objetivos ligados aos campos de experiência dependerão, sob medida, de como o Projeto Político Pedagógico das diferentes unidades de educação infantil é colocado em prática. Em outras palavras, a composição das equipes docentes atuantes nessas unidades, com a presença de especialistas, somente tenderia a uma fragmentação dos conhecimentos abordados, ou mesmo a uma disciplinarização dos tempos pedagógicos, caso a própria Unidade, em seu PPP, apontasse tal dinâmica como pressuposto para o cotidiano pedagógico.

Contudo, tendo em vista os conhecimentos acumulados na esfera da produção acadêmica especificamente voltada para as relações entre Educação Física e educação infantil ${ }^{7}$, é possível chegar a consensos razoáveis em torno do papel desempenhado por esses professores na primeira etapa da educação básica e como deve se dar a articulação do seu trabalho no âmbito das equipes docentes nas unidades educativas. De acordo com Sayão (2002),

[...] para pensar a Educação Física no âmbito do trabalho pedagógico com crianças de pouca idade, faz-se necessário articular diferentes áreas do conhecimento e diferentes profissionais. [...] Assim como na construção de um mosaico, estes profissionais vão articulando saberes e práticas que não podem ficar reduzidos a uma única disciplina ou a uma única área do conhecimento" (SAYÃO, 2002, p. 65).

Por isso, almeja-se que possa ocorrer uma partilha de saberes e abordagens pedagógicas visando a um mútuo aprendizado, assumindo a figura do professor de Educação Física como mais um adulto a interagir com as crianças na Unidade Educativa (BUSS SIMÃO, 2005). Do mesmo modo, é desejável que a Educação Física componha um projeto institucional da Unidade

\footnotetext{
${ }^{7}$ Ver, por exemplo, Silveira (2015); Mello et al (2016), Macedo e Neira (2017), Souza (2019).
} 
Educativa construído coletivamente, visando unificar processos de aprendizagem e a integração de saberes entre os professores (MELLO et al, 2018). E, também, compreender que a Educação Física qualifica suas ações ao estabelecer parcerias a partir do diálogo entre as práticas pedagógicas articuladas entre si, visando, em última instância, ao desenvolvimento integral das crianças (SOARES, PRODOCIMO, DE MARCO, 2016).

De fato, é necessário considerar que, uma vez inseridos nesse contexto pedagógico, todos os professores, independentemente de sua área de formação, são professores atuantes na educação infantil. Ou seja, sua atividade docente precisa corresponder com as especificidades pedagógicas de crianças de zero a cinco anos, assim como ser coerente com as expectativas curriculares expressas nos documentos orientadores das diferentes redes de ensino (que, atualmente, precisam ser coerentes com a BNCC). Partindo de tal pressuposto, é necessário que as relações pedagógicas se estruturem a partir da perspectiva de uma docência compartilhada (DUARTE, 2011), através da qual os diferentes profissionais partilhem metas, ações e, assim, contribuam para as aprendizagens e desenvolvimento das crianças.

E, nesse sentido, o próprio espectro de ações pedagógicas da Educação Física se amplia, englobando elementos inerentes a outros campos de experiência ou linguagens, e, também, incorporando, ao seu fazer pedagógico, outros aspectos inerentes ao cotidiano da educação de zero a cinco anos, como a alimentação, higiene, descanso e bem-estar das crianças.

Parece evidente que tal perspectiva de atuação docente precisa ser construída no cotidiano das unidades educativas, demandando encontros, conversas, partilhas e mútuos aprendizados. Em quais condições esses tempos e espaços forjados no cotidiano pedagógico serão conquistados, dependerá de uma série de questões, como a conciliação dos momentos de hora atividade $^{8}$, de uma articulação por parte da supervisão/coordenação pedagógica da Unidade, assim como da própria disponibilidade dos professores para aprender e fazer com o outro.

De acordo com o estudo realizado por Mello et al (2018), dentre os principais desafios para articular a Educação Física ao projeto institucional da Unidade Educativa, está a ausência de tempos/espaços institucionalizados para o diálogo entre os professores no sentido de encaminhar ações conjuntas. Nessa perspectiva, a própria organização da Unidade Educativa,

\footnotetext{
${ }^{8}$ A hora-atividade se estrutura de formas diferentes nos mais variados contextos estaduais e municipais no Brasil afora, e, certamente, ainda não se constitui em uma realidade para todos os professores do País. Refere-se a um terço da jornada semanal de trabalho dos professores, dedicado ao planejamento, ao estudo e à formação continuada, conforme previsto na Lei 11.738/2008 (BRASIL, 2008) - que institui o piso salarial profissional nacional para os profissionais do magistério público da educação básica.
} 
na intenção de propiciar os encontros, é uma atitude pedagogicamente louvável, mas que se torna uma tarefa ainda mais difícil quando envolve a conciliação dos momentos de hora atividade, quando a presença do professor de Educação Física, em sala, acaba implicando ausência da pedagoga e vice-versa. Se somarmos a isso o fato de os professores de Educação Física, geralmente, atuarem em muitos grupos de crianças, possibilitar os encontros e diálogos com as diferentes pedagogas se torna praticamente inviável.

Para além da organização em torno dos momentos de discussão entre pares, a própria realização de discussões com base nas especificidades pedagógicas da Educação Física, na educação infantil, acaba sendo prejudicada em face da pouca proximidade com as discussões da produção acadêmica da área entre os pedagogos/supervisores. E soma-se a isso algumas representações sobre Educação Física que acabam travando o debate em torno de suas ações no cotidiano pedagógico, sobretudo, aquelas pautadas em parcerias.

No que tange às citadas representações, em pesquisa realizada por Mello et al (2012), por exemplo, apontou-se que as pedagogas concebem os momentos de Educação Física como momento de folga e descanso para elas; como disciplina auxiliar; e como tendo um papel secundário na educação infantil; revelando certos equívocos em suas representações sobre o papel social da Educação Física, possivelmente ligados às suas próprias experiências no âmbito da vida escolar. Nessa perspectiva, outro desafio a ser superado é a interpretação de que a inserção da Educação Física, nas Unidades Educativas, serve, apenas, como um meio para se assegurar a sua própria organização pedagógica. Tal fato resulta que "a falta de articulação entre os saberes presentes na Educação Infantil tem sido favorecida pela incompreensão acerca do papel da Educação Física, cuja função é vista como um meio para suprir as demandas de planejamento individual das professoras regentes" (MELLO et al, 2018, p.19).

Outro ponto é que, dentro das Unidades Educativas, podem existir dificuldades nos diálogos entre as equipes pedagógicas e os professores de Educação Física, visando a um alinhamento em torno de expectativas curriculares. E assim sendo, como consequência, é possível que diferentes práticas e concepções pedagógicas sejam realizadas sob o manto da Educação Física na educação infantil. Daí a importância de os professores de Educação Física construírem diálogos entre as especificidades da sua formação docente com as demandas curriculares próprias da educação infantil, encabeçando esse debate sobre como a Educação Física é desenvolvida na Unidade Educativa (SILVEIRA, 2015).

Todavia, esse processo depende, diretamente, da capacidade dos professores de Educação Física se inserirem nesse debate, com seus acúmulos teóricos e saberes docentes, que 
são ligados à sua própria formação. Nesse ínterim, é preciso considerar que existe certo consenso entre professores dessa área quanto à insuficiência dos currículos das licenciaturas no que tange à uma preparação para atuar na educação de zero a cinco anos (GUIRRA; PRODOCIMO, 2010). Inclusive, com relatos acerca de "uma lacuna em seu processo de formação inicial, com relação a oferta de uma disciplina específica para problematizar a Educação Infantil” (PERINI; BRACHT, 2016, p.956).

Em que pese a importância da formação inicial para a carreira docente, como dito antes, o processo de formação de professores assume um caráter permanente, com peso inegável das próprias experiências docentes e, também, dos processos de formação continuada. Por isso, os momentos de formação continuada, sobretudo, no que tange à troca de saberes com colegas professores da mesma área, tende a ser uma proposta interessante para se refletir sobre o cotidiano pedagógico da educação infantil e abordar a Educação Física a partir de um olhar que foque na sua especificidade, mas que dialogue com as expectativas curriculares da educação de zero a cinco anos. Segundo Perini e Bracht (2016),

[...] compreendemos esse espaço como uma oportunidade efetiva de construção, desconstrução e reconstrução do conhecimento docente. Por via dos dilemas e desafios coletivos enfrentados nos cotidianos escolares, esse processo formativo representa uma das ferramentas que pode contribuir para uma permanente atualização dos conhecimentos, do desenvolvimento profissional e a possível qualificação do processo de ensino-aprendizagem (PERINI; BRACHT, 2016, p.957).

Enfim, trata-se de uma oportunidade para qualificar o trabalho docente, em que a troca de experiências pautada na solidariedade entre colegas de uma mesma área e outros profissionais atuantes na educação infantil viabilizam uma reflexão constante sobre a docência (SAYÃO, 2002). E assim sendo, pode contribuir, decisivamente, para se qualificar os debates acerca da construção de uma Educação Física que se pretende "com a educação infantill".

\section{CONSIDERAÇÕES FINAIS}

As reflexões realizadas, no presente ensaio, pautaram-se na inserção dos professores de Educação Física, no cotidiano pedagógico da educação infantil, como forma de propiciar a qualificação do trato pedagógico com o corpo em movimento e contribuir, assim, para o desenvolvimento integral das crianças de zero a cinco anos.

A compreensão do movimento humano como linguagem e forma preponderante de 
expressão, por parte das crianças, parece indicar que as práticas pedagógicas, nessa etapa da educação básica, são enriquecidas com a presença de professores cuja especificidade de formação tem como centralidade o corpo em movimento. De modo concomitante, ao articular suas especificidades pedagógicas com as expectativas curriculares da educação infantil, a própria atuação dos (as) professores (as) de Educação Física acaba se transformando didática e pedagogicamente. Isso porque, as reflexões acerca de tais demandas curriculares, sobre as especificidades etárias e sobre o modo de se vivenciar os momentos de Educação Física com as crianças nessa etapa da educação básica se tornam uma constante no cotidiano pedagógico.

Ao refletirmos sobre o direito das crianças à ampliação de seu repertório cultural com base em uma cultura corporal de movimentos, percebe-se que as contribuições pedagógicas dos professores de Educação Física tornam-se ainda mais necessárias. Todavia, alguns desafios ainda precisam ser enfrentados quanto à inserção da Educação Física na educação infantil, como a superação de representações equivocadas quanto ao seu papel, o debate acerca da articulação entre suas especificidades e as demandas curriculares da educação de zero a cinco anos, e os esforços acerca da construção de uma docência compartilhada.

\section{REFERÊNCIAS}

AYOUB, Eliana. Narrando experiências com a educação física na educação infantil. In: Revista Brasileira de Ciências do Esporte, Campinas, v.26, n.3, p.143-158, maio 2005.

BRASIL. Base Nacional Comum Curricular. Ministério da Educação. Brasília: MEC, 2018. Disponível em: <http://basenacionalcomum.mec.gov.br/\#/site/inicio〉. Acesso em: 10 mar. 2021.

BRASIL. Lei 11.738 de 16 de julho de 2008. Brasília, 2008. Disponível em: http://www.planalto.gov.br/ccivil_03/_ato2007-2010/2008/lei/111738.htm. Acesso em: 30/06/2021. BUSS-SIMÃO, Márcia. Educação física na educação infantil: refletindo sobre a "hora da educação física”. Motrivivência, Florianópolis, n. 25, p. 163-173, jan. 2005.

DUARTE, Fabiana. Professoras de bebês: as dimensões educativas que constituem a especificidade da ação docente. 2011. Dissertação (Mestrado) — Centro de Ciências da Educação, Universidade Federal de Santa Catarina, 2011.

FARIAS, Uirá de Siqueira et al. Análise da produção do conhecimento sobre a educação física na educação infantil. Movimento (ESEFID/UFRGS), Porto Alegre, p. e25058, out. 2019. ISSN 19828918. Disponível em: 〈https://seer.ufrgs.br/Movimento/article/view/90145>. Acesso em: 01 jul. 2021. GUIRRA, Frederico Jorge Saad; PRODOCIMO, Elaine. Trabalho corporal na educação infantil: afinal, quem deve realizá-lo? Motriz: rev. educ. fis. (Online), Rio Claro, v. 16, n. 3, pág. 708-713, setembro de 2010.

MACEDO, Elina Elias de; NEIRA, Marcos Garcia. A Educação Física na creche: tematizando as práticas corporais. Revista Brasileira de Educação Física e Esporte, [S. l.], v. 31, n. 1, p. 99-106, 2017.

MELLO, André da Silva et al. Representações sociais sobre a educação física na educação 
infantil. Rev. educ. fis. UEM, Maringá, v. 23, n. 3, p. 443-455, Sept. 2012.

MELLO, André da Silva. et al. A educação infantil na Base Nacional Comum Curricular: pressupostos e interfaces com a Educação Física. Motrivivência, Florianópolis, v. 28, n. 48, p. 130-149, set. 2016.

MELLO, André da Silva, et al. Educação Física na Educação Infantil: Do isolamento pedagógico à articulação com outras áreas do conhecimento. Kinesis [Online], v.36, n.3. 2018. Acesso em 19 Mar. 2021

NOGUEIRA, Quéfren Weld Cardozo. Educação física, cultura e a produção de significados. Educar em Revista [online]. 2005, n. 26 [Acessado 1 Julho 2021] , pp. 197-214. Disponível em: <https://doi.org/10.1590/0104-4060.392>.

OLIVEIRA, Luciana Dias de; PRODÓCIMO, Elaine. A prática do professor de educação física na educação infantil. Corpoconsciência, [S. l.], v. 19, n. 2, p. 37-48, 2016.

OTA, Giovanna Sayuri Garbelini. Histórias vivenciadas: ações interdisciplinares da educação física na educação infantil. Dissertação (Mestrado). Programa de Pós-Graduação em Educação Física. Universidade Estadual de Campinas, 2020.

PERINI, Rosileia; BRACHT, Valter. Os saberes docentes dos professores de educação física na educação infantil de Serra/ES. Pensar a Prática, v. 19, n. 4, 28 dez. 2016.

SAYÃO, Débora Tomé. Corpo e movimento: notas para problematizar algumas questões relacionadas à educação infantil e a educação física. Revista Brasileira de Ciências do Esporte, v. 23, n.2, p. 5567, jan. 2002.

SILVEIRA, Juliano. Reflexões sobre a presença da Educação Física na primeira etapa da educação básica. Motrivivência, v. 27, n. 45, p. 13-27, 2015.

SOARES, Daniela Bento; PRODÓCIMO, Elaine; DE MARCO, Ademir. O diálogo na educação infantil: o movimento, a interdisciplinaridade e a educação física. Movimento (ESEFID/UFRGS), Porto Alegre, p. 1195-1208, dez. 2016.

SOUZA, Bárbara Isabela Soares de. A organização do trabalho pedagógico na educação infantil: especificidades e relações com a Educação Física. Motrivivência, (Florianópolis), v. 31, n. 58, p. 0122, abril/julho, 2019. 